\title{
DISTRIBUSI HARA DALAM TANAH DAN PRODUKSI AKAR TANAMAN KELAPA SAWIT PADA METODE PEMUPUKAN YANG BERBEDA
}

\author{
Edy Sigit Sutarta, Winarna, Muhammad Arif Yusuf \\ Coressponding outhor : edy sigit@yahoo.com
}

\begin{abstract}
The effectiveness of fertilization, could be influenced by the type of fertilizer and the right method. There are several methods of fertilization, such as fertilizer aplied in pockets and scattered. Relations fertilization method with root distribution of oil palm plantations and nutrients in the soil need to be known, so it can be determined in a more effective method of fertilization for oil palm plantations. The observation was performed 1 year after application, includes observation of the soil (physical and chemical properties) and the observation of the root (primary root, secondary, tertiary). Examples of soil and roots were taken at depths of $00-20 \mathrm{~cm}, 20-40 \mathrm{~cm}, 40-60 \mathrm{~cm}, 60-80 \mathrm{~cm}$, and $80-100 \mathrm{~cm}$ at a distance of $50 \mathrm{~cm}, 100 \mathrm{~cm}$, $150 \mathrm{~cm}, 200 \mathrm{~cm}, 250 \mathrm{~cm}, 300 \mathrm{~cm}, 350 \mathrm{~cm}, 400 \mathrm{~cm}$ from the base of the stem. The results showed that the distribution of nutrients in the soil surface is greater than the layer underneath and root production decreased due to lower soil layers.
\end{abstract}

Keywords: palm oil, nutrient distribution, root production, fertilization

\begin{abstract}
ABSTRAK
Efektifitas pemupukan, salah satunya dapat di pengaruhi oleh jenis pupuk dan metode yang tepat. Ada beberapa metode pemupukan, antara lain pupuk sebar dan pupuk pocket. Hubungan metode pemupukan dengan distribusi akar tanaman kelapa sawit dan hara dalam tanah perlu diketahui, sehingga dapat ditentukan metode pemupukan yang lebih efektif untuk perkebunan kelapa sawit. Pengamatan dilakukan 1 tahun setelah aplikasi, meliputi pengamatan tanah (sifat fisik dan kimia) dan pengamatan akar (akar primer, sekunder, tersier). Contoh tanah dan akar diambil pada kedalaman $0-20 \mathrm{~cm}, 20-40 \mathrm{~cm}, 40-60 \mathrm{~cm}$, $60-80 \mathrm{~cm}$, dan $80-100 \mathrm{~cm}$ pada jarak $50 \mathrm{~cm}, 100 \mathrm{~cm}, 150 \mathrm{~cm}, 200 \mathrm{~cm}, 250 \mathrm{~cm}, 300 \mathrm{~cm}$, $350 \mathrm{~cm}, 400 \mathrm{~cm}$ dari pangkal batang. Hasil penelitian menunjukkan bahwa sebaran hara pada permukaan tanah lebih besar dibandingkan dengan lapisan bawahnya dan produksi akar semakin menurun seiring dengan penurunan lapisan tanah.
\end{abstract}

Kata kunci : kelapa sawit, distribusi hara, produksi akar, pemupukan

PENDAHULUAN

Produktivitas tanaman kelapa sawit sangat dipengaruhi oleh ketersediaan unsur hara dalam tanah. Ketersediaan hara yang cukup bagi tanaman bermanfaat mendorong pertumbuhan vegetatif tanaman yang sehat dan produksi TBS secara maksimum dan ekonomis, serta meningkatkan ketahanan terhadap hama penyakit. Ketersediaan hara dalam tanah tidak selalu cukup dan perlu penambahan unsur hara dalam bentuk pupuk. Efektifitas pemupukan dipengaruhi oleh jenis dan metode penempatan pupuk. Jenis pupuk yang umum digunakan pada kelapa sawit 
yaitu pupuk tunggal dan majemuk dengan tingkat efektifitas yang berbeda. Penempatan pupuk yang tepat pada bagian perakaran yang efektif untuk menyerap hara merupakan salah satu upaya agar pemupukan berhasil guna dan berdaya guna. Ada beberapa metode pemberian pupuk pada tanaman, antara lain dengan cara ditabur dan dengan cara pocket. Pemberian pupuk dengan cara ditabur dilakukan dengan cara menebar pupuk pada piringan dengan radius 1,5 meter dari titik tanam. Pocket dibuat dengan cara membuat lubang pada piringan yang kemudian dijadikan sebagai tempat meletakkan pupuk. Selain pemilihan metode pemupukan yang tepat, penambahan bahan organik seperti tandan buah kosong berpotensi membantu penyerapan pupuk secara efektif (Kheong et al., 2010).

Jumlah hara yang banyak bukan menjadi jaminan dapat diserap oleh akar. Dalam mekanisme penyerapan unsur hara oleh tanaman, akar merupakan organ tanaman yang berfungsi menyerap unsur hara dari dalam tanah. Widyastuti et al. (2003) menyatakan bahwa akar merupakan salah satu faktor penting dalam menentukan produktivitas tanaman. Semakin ekstensif sistem perakaran maka semakin tinggi efisiensi penyerapan hara dan air oleh tanaman.

Berdasarkan ukurannya, akar kelapa sawit dibagi menjadi 4 (empat) bagian yaitu 1) akar primer yaitu akar yang tumbuh vertikal (radicle) maupun mendatar (adventitious roots), berdiameter 6 - $10 \mathrm{~mm}$; 2) akar sekunder yaitu akar yang tumbuh dari akar primer, arah tumbuhnya mendatar maupun ke bawah, berdiameter $2-4 \mathrm{~mm}$; 3) akar tersier yaitu akar yang tumbuh dari akar sekunder, arah tumbuhnya mendatar, panjangnya mencapai 0,7 - $2 \mathrm{~mm}$; 4) akar kuarter yaitu akar-akar cabang dari akar tertier, berdiameter $0,1-0,3 \mathrm{~mm}$ dan panjangnya rata-rata $3 \mathrm{~cm}$ (Lubis, 2008).

Penyerapan hara dilakukan oleh bulu-bulu akar, sedangkan bagian lain akar seperti tudung akar, cabang akar hanya mampu menyerap hara dalam jumlah kecil. Penyerapan unsur hara paling efektif dilakukan oleh akar tersier dan kwarter yang disebut feeding roots berdiameter kurang lebih 0.2 - 1.2 milimeter yang umumnya lebih banyak terdapat pada tanah lapisan atas (top soil) (Tinker, 1976). Panjang pendeknya lintasan penyerapan hara dipengaruhi oleh faktor-faktor genetis dan juga faktor-faktor luar (lingkungan) seperti keras lunaknya tanah, banyak sedikitnya air, jauh dekatnya air tanah dan lain-lain. Penyerapan hara oleh bulu-bulu akar juga dipengaruhi oleh suhu tanah, kelembaban tanah dan aerasi tanah. (Riata, 2010).

Pergerakan atau distribusi akar dalam tanah berhubungan dengan ketersediaan air dan ketersediaan unsur hara (Machado et al., 2003). Hubungan metode pemupukan dengan distribusi akar tanaman kelapa sawit dan hara dalam tanah perlu diketahui, sehingga dapat ditentukan metode pemupukan yang lebih efektif untuk perkebunan kelapa sawit.

\section{BAHAN DAN METODE}

Penelitian dilakukan di Kebun Penelitian Bukit Sentang pada tanaman sawit tahun tanam 1998. Areal penelitian merupakan lahan dengan topografi bergelombang. Perlakuan pada penelitian ini meliputi aplikasi metode pocket dengan jenis pupuk majemuk dan metode sebar dengan jenis pupuk tunggal. Metode pocket dilakukan dengan cara membuat lubang pada piringan pohon sebanyak 4 buah per pohon dengan jarak $\pm 100 \mathrm{~cm}$ dari pangkal pohon. Dosis pupuk majemuk yang diberikan sebanyak $5 \mathrm{~kg}$ pupuk majemuk $+4 \mathrm{~kg}$ dolomit/pohon/tahun. Aplikasi dolomit dilakukan dengan cara disebar pada piringan pohon. Aplikasi pupuk dengan cara sebar, dilakukan dengan menebar pupuk tunggal pada piringan pohon pada jarak 1,5 meter dari pangkal pohon kearah 
luar piringan pohon. Dosis pupuk tunggal yang diberikan:

$$
\begin{array}{lll}
\text { - Urea } & : & 2,5 \\
& \text { kg/pohon/tahun } \\
\text { - } & \text { TSP } & : 2 \mathrm{~kg} / \text { pohon/tahun } \\
\text { - } & \text { MOP } & : 2 \mathrm{~kg} / \text { pohon/tahun } \\
\text { - } & \text { Dolomit } & : 4 \mathrm{~kg} / \text { pohon/tahun } \\
& \text { Pengamatan } & \text { dilakukan 1 tahun }
\end{array}
$$
setelah aplikasi, meliputi pengamatan tanah (sifat fisik dan kimia) dan pengamatan akar (akar primer, sekunder, tersier). Contoh tanah diambil pada kedalaman $0-20 \mathrm{~cm}, 20-40 \mathrm{~cm}, 40-60$ $\mathrm{cm}, 60-80 \mathrm{~cm}$, dan $80-100 \mathrm{~cm}$ pada jarak $50 \mathrm{~cm}, 100 \mathrm{~cm}, 150 \mathrm{~cm}, 200 \mathrm{~cm}, 250$ $\mathrm{cm}, 300 \mathrm{~cm}, 350 \mathrm{~cm}, 400 \mathrm{~cm}$ dari pangkal batang. Khusus pengambilan sample tanah tidak terganggu (ring sample) hanya di bedakan berdasarkan kedalaman $(0-20$ $\mathrm{cm}, 20-40 \mathrm{~cm}, 40-60 \mathrm{~cm}, 60-80 \mathrm{~cm}$, dan $80-100 \mathrm{~cm}$ )
Pengambilan sample akar dilakukan pada $1 / 8$ area piringan pohon (gambar 1), namun dalam pengolahan data dikalikan dengan faktor pengali 8, sehingga diasumsikan tetap satu piringan. Pengamatan distribusi akar yaitu dengan memisahkan setiap jenis akar (primer, sekunder, dan tersier) juga dilakukan pada jarak dan kedalaman seperti pada pengambilan sample tanah. Akar kwater dalam penelitian ini dimasukkan dalam jenis akar tersier karena terlalu sulit dalam pemisahannya. Contoh tanah selanjutnya dianalisis di laboratorium, meliputi analisis fisika dan kimia tanah. Perakaran kelapa sawit yang telah diambil kemudian dioven untuk mengetahui berat keringnya. Data berat kering akar ini akan digunakan untuk menghitung produksi akar dan distribusinya.

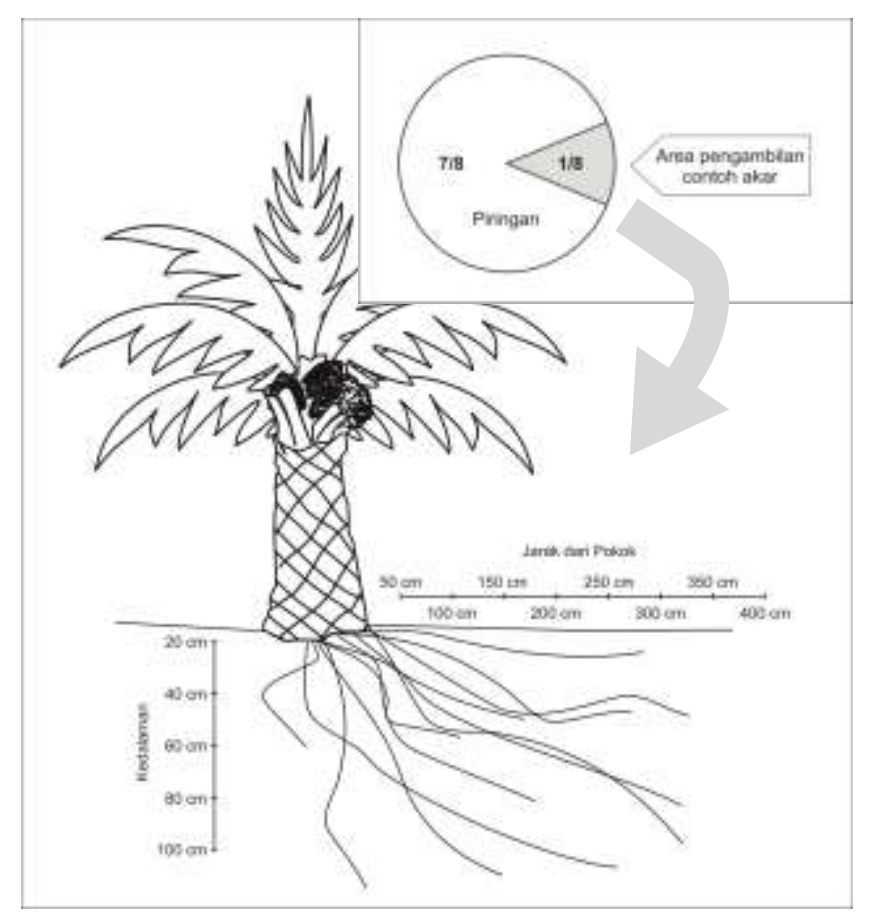

Gambar 1. Penampang melintang pengambilan contoh tanah akar pada penelitian.

\section{HASIL PEMBAHASAN}

\section{Sifat Fisik Tanah}

Sifat fisik tanah antara lain terdiri dari kerapatan jenis partikel, bobot isi tanah kering, porositas tanah, tekstur tanah, struktur tanah, kadar air tanah, konsistensi tanah, dan lain sebagainya.
Pada penelitian ini pengamatan sifat fisik hanya terbatas pada kadar air lapang, BD, ruang pori, kadar air, pori drainase, air tersedia, dan permeabilitas..

Menurut Soil Survey Staff USDA (2003), tanah terdiri dari padatan (Mineral 
dan bahan organik), cair, dan gas, yang menempati ruang. Ruang pori adalah bagian dari tanah yang ditempati air dan udara. Jumlah ruang pori sebagian ditentukan oleh susunan butir-butir padat, apabila letak keduannya cenderung erat, seperti pada pasir atau subsoil yang padat, total porositasnya rendah. Tanah bertekstur halus akan mempunyai persentase pori total lebih tinggi dari pada bertekstur kasar. Hasil analisis sifat fisik tanah pada penelitian ini menunjukkan bahwa ruang pori total pada tanah perlakuan pupuk pocket dengan pupuk majemuk lebih besar dibandingkan pupuk sebar dengan pupuk tunggal yaitu sebesar 52,79 pada kedalaman $0-20$. Hal ini dapat diartikan bahwa tanah pada perlakuan pupuk pocket dengan pupuk majemuk lebih gembur, memiliki porositas lebih besar, dan juga memiliki tekstur yang lebih halus. Hasil penelitian Yahya et al. (2010) menyatakan bahwa kepadatan tanah berpengaruh terhadap pertumbuhan akar kelapa sawit.

Tabel 1. Hasil analisis sifat fisik pada perlakuan pocket dengan pupuk majemuk

\begin{tabular}{|c|c|c|c|c|c|c|c|c|}
\hline Kedalaman & Kadar air & $\mathrm{BD}$ & $\begin{array}{c}\text { Ruang } \\
\text { pori }\end{array}$ & Kadar Air & \multicolumn{2}{|c|}{ Pori drainase } & air & Permeabilitas \\
\hline$(\mathrm{cm})$ & lapang & $\mathrm{g} / \mathrm{cc}$ & total & $\mathrm{pF} 2.54$ & Cepat & Lambat & tersedia & $\mathrm{cm} / \mathrm{jam}$ \\
\hline & (\% vol.) & & & \multicolumn{5}{|c|}{$\%$ Volume } \\
\hline $0-20$ & 48,38 & 1,21 & 52,79 & 37,72 & 10,79 & 4,27 & 14,72 & 7,85 \\
\hline $20-40$ & 41,48 & 1,36 & 47,81 & 36,97 & 7,25 & 3,59 & 13,38 & 0,34 \\
\hline $40-60$ & 48,47 & 1,28 & 50,20 & 40,55 & 6,01 & 3,63 & 11,60 & 5,94 \\
\hline $60-80$ & 47,54 & 1,30 & 47,59 & 37,05 & 6,58 & 3,95 & 6,20 & 0,20 \\
\hline $80-100$ & 49,68 & 1,33 & 49,43 & 38,83 & 6,98 & 3,63 & 7,64 & 5,19 \\
\hline
\end{tabular}

TabeL 2. Hasil analisis sifat fisik pada perlakuan sebar dengan pupuk tunggal

\begin{tabular}{|c|c|c|c|c|c|c|c|c|}
\hline $\begin{array}{c}\text { Kedalaman } \\
(\mathrm{cm})\end{array}$ & $\begin{array}{c}\text { Kadar } \\
\text { air }\end{array}$ & $\mathrm{BD}$ & $\begin{array}{c}\text { Ruang } \\
\text { pori }\end{array}$ & $\begin{array}{c}\text { Kadar } \\
\text { Air }\end{array}$ & \multicolumn{2}{|c|}{ Pori drainase } & air & Permeabilitas \\
\cline { 2 - 9 } & lapang & $\mathrm{g} / \mathrm{cc}$ & total & $\mathrm{pF} 2.54$ & Cepat & Lambat & tersedia & $\mathrm{cm} /$ jam \\
\hline & (\% vol.) & & & \multicolumn{5}{|c|}{$\%$ Volume } \\
\hline $0-20$ & 40,99 & 1,33 & 46,94 & 34,85 & 8,19 & 3,90 & 8,44 & 3,52 \\
\hline $20-40$ & 35,84 & 1,49 & 43,23 & 32,24 & 8,30 & 2,68 & 8,81 & 0,90 \\
\hline $40-60$ & 41,00 & 1,49 & 44,08 & 30,91 & 8,72 & 4,45 & 7,09 & 0,68 \\
\hline $60-80$ & 38,82 & 1,41 & 45,04 & 30,93 & 9,81 & 4,30 & 8,75 & 0,17 \\
\hline $80-100$ & 36,67 & 1,45 & 43,37 & 30,10 & 7,60 & 5,67 & 8,06 & 2,30 \\
\hline
\end{tabular}

\section{Distribusi Hara dalam Tanah}

Aplikasi pemupukan baik pada perlakuan sebar maupun perlakuan pocket dilakukan di tanah lapisan atas. Unsur Hara yang diamati meliputi unsur N, P, K, $\mathrm{Mg}$, dan Ca. Dari hasil pengamatan, dapat dilihat bahwa pada perlakuan pupuk sebar dengan menggunakan pupuk tunggal maupun perlakuan pocket dengan menggunakan pupuk majemuk memiliki pola distribusi hara yang sama. Gambar 1 menunjukkan bahwa distribusi hara pada kedalaman $0-20 \mathrm{~cm}$ memiliki status hara yang lebih tinggi jika dibandingkan dengan kedalaman dibawahnya yaitu kedalaman $20-40 \mathrm{~cm}$. Hal ini dimungkinkan karena aplikasi pupuk dilakukan di lapisan atas, sehingga sebaran hara pada lapisan atas lebih besar dibandingkan pada lapisan bawahnya.

Distribusi unsur hara pada perlakuan sebar dan pupuk tunggal secara umum memiliki pola yang sama. Distribusi kandungan hara tertinggi rata rata berada pada jarak $\pm 150 \mathrm{~cm}$ (Gambar 3) dari pangkal pohon dengan kedalaman 0 - 20 (Gambar 2). Hal ini dimungkinkan karena aplikasi pupuk dengan cara sebar menggunakan pupuk tunggal dilakukan pada piringan berjarak $150 \mathrm{~cm}$ dari pangkal pohon, sehingga konsentrasi hara terbesar berada pada area tersebut. 
Unsur hara $\mathrm{N}$ memiliki sifat higroskopis yang mudah menguap. Ketersediaannya dalam tanah tergantung dari hidrolisa yang sangat dipengaruhi oleh aktifitas mikroorganisme. Dari sifat $\mathrm{N}$ tersebut maka distribusi unsur $\mathrm{N}$ dapat lebih mudah tersebar merata pada piringan dan daerah sekitar piringan. Hasil analisis unsur kimia pada perlakuan pupuk sebar menunjukkan bahwa distribusi unsur $\mathrm{N}$ pada kedalaman $0-20 \mathrm{~cm}$ dengan jarak dari pohon $50-400 \mathrm{~cm}$ tersebar hampir merata. Distribusi unsur $\mathrm{N}$ memiliki nilai berkisar antara $0,09-0,15 \%$. Pada kedalaman $20-40 \mathrm{~cm}$, distribusi unsur $\mathrm{N}$ masih memiliki pola yang sama dengan kedalaman diatasnya $(0-20 \mathrm{~cm})$, hanya saja nilainya lebih rendah yaitu berkisar antara $0,05-0,11 \%$. Ketersediaan unsur $\mathrm{P}$ dalam tanah sangat banyak, namun yang tersedia bagi tanaman sangat sedikit. Unsur $\mathrm{P}$ sangat mudah untuk diikat oleh unsur $\mathrm{Fe}$, $\mathrm{Al}$, dan $\mathrm{Ca}$ sehingga sulit untuk diserap oleh tanaman. Gambar 2 menunjukkan bahwa distribusi unsur $\mathrm{P}$
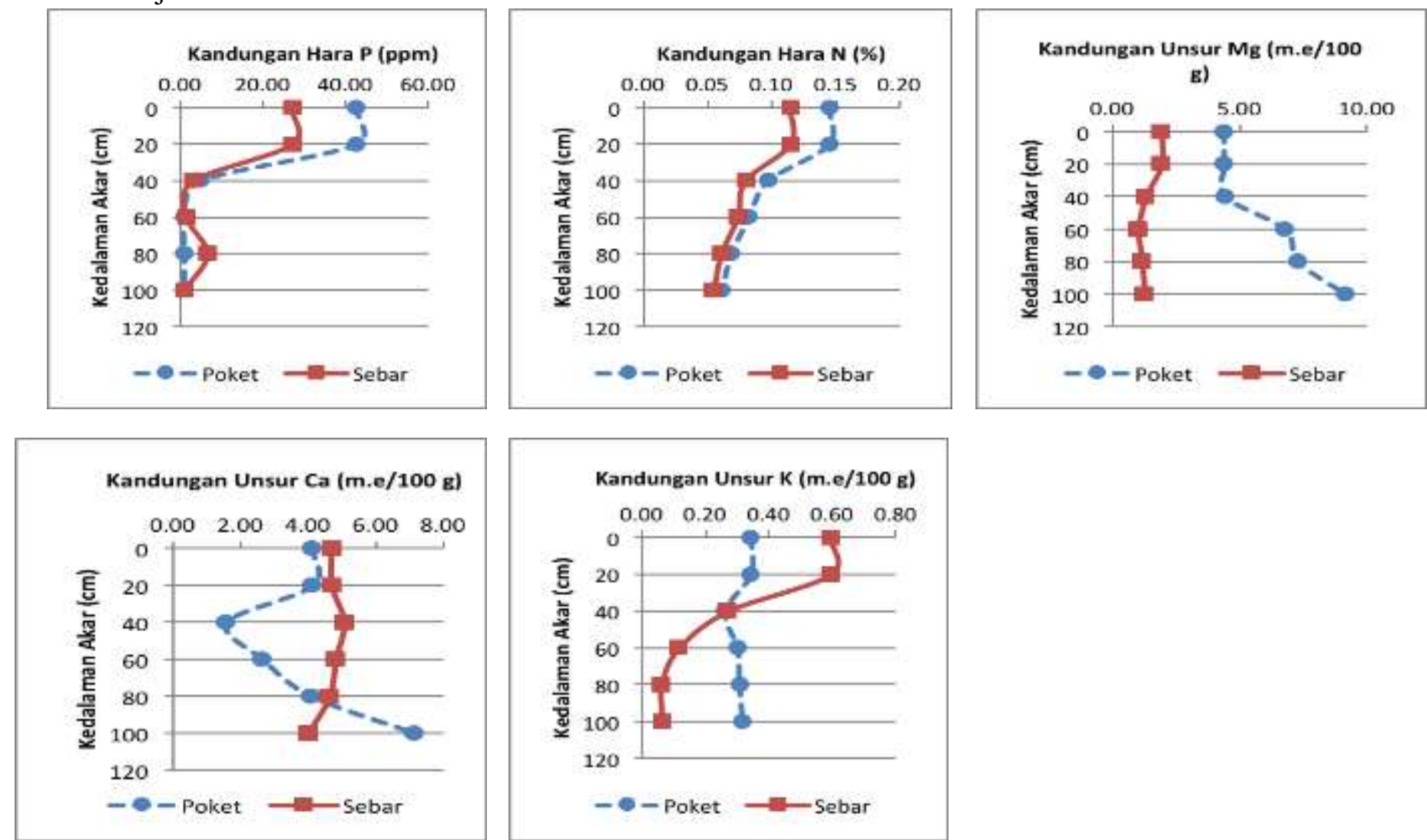

Gambar 2. Kandungan unsur hara setiap kedalaman pada perlakuan pupuk poket dan pupuk sebar. 

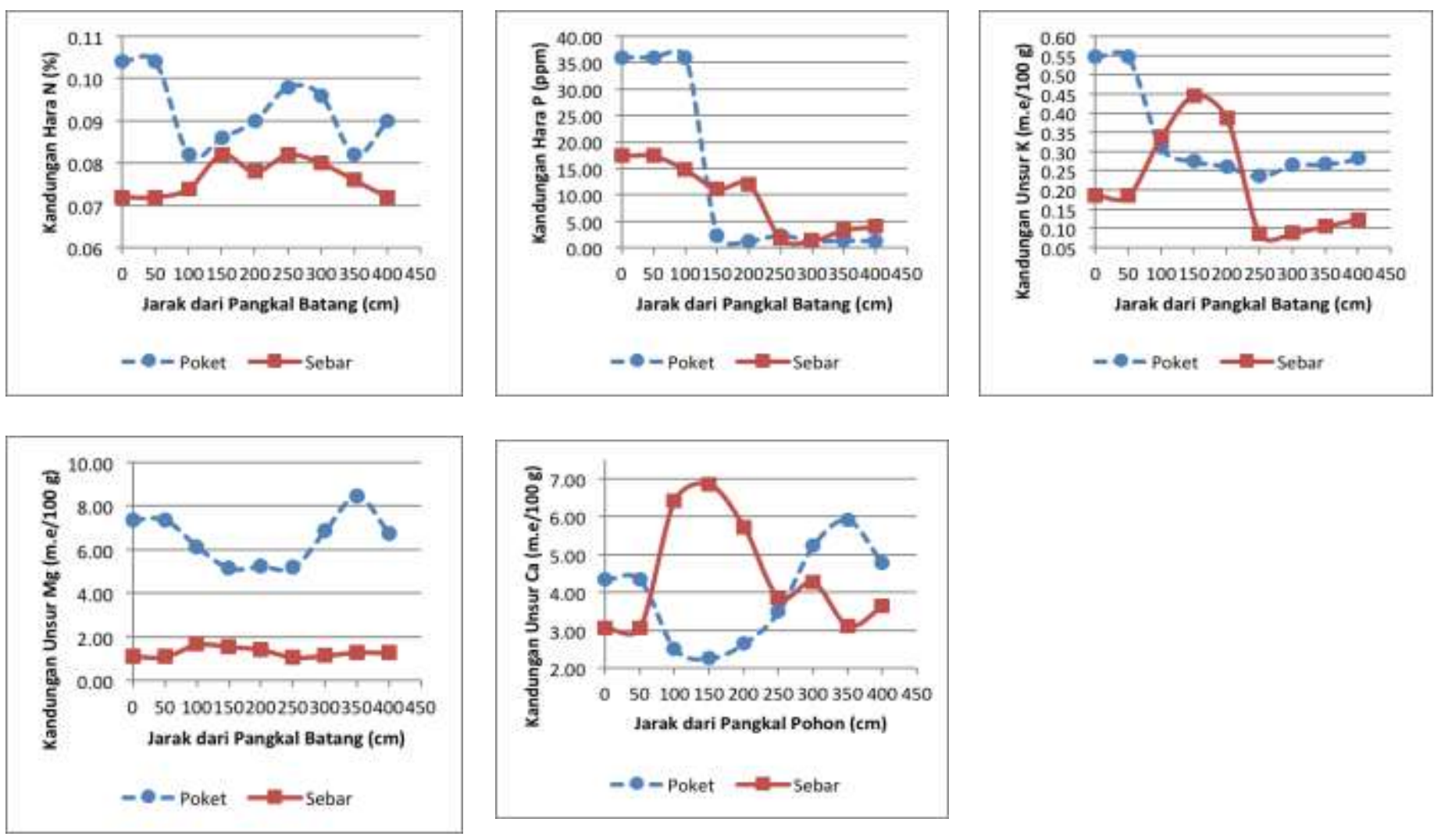

Gambar 3. Sebaran unsur hara pada beberapa jarak dari pangkal pohon

Pola sebaran unsur $\mathrm{N}$ dan $\mathrm{P}$ pada perlakuan pocket, hampir sama dengan pola sebaran unsur $\mathrm{N}$ dan $\mathrm{P}$ pada perlakuan pupuk sebar. Unsur hara $\mathrm{N}$ tersebar merata pada piringan dan daerah sekitar piringan. Besarnya kandungan unsur $\mathrm{N}$ pada kedalaman $0-20 \mathrm{~cm}$ tidak berbeda jauh nilainya dengan kedalaman $20-40 \mathrm{~cm}$. Unsur $\mathrm{P}$ memiliki nilai yang tinggi dilapisan atas. Hal ini dapat disebabkan karena kandungan unsur $\mathrm{Al}$ dan $\mathrm{Fe}$ di lapisan atas sedikit, sehingga unsur $\mathrm{P}$ tersedia belum terjerap oleh unsur - unsur tersebut. Sebaran hara P terbanyak berada pada jarak $100 \mathrm{~cm}$ dan $50 \mathrm{~cm}$ (Gambar 3). Hasil analisis unsur hara pada perlakuan pupuk pocket dengan menggunakan pupuk majemuk selengkapnya dapat dilihat pada Lampiran 2.

\section{Distribusi Akar pada Tanaman Kelapa Sawit}

Distribusi akar primer, sekunder dan tersier pada kedalaman $0-100 \mathrm{~cm}$ memiliki pola yang sama, baik pada perlakuan pupuk sebar maupun perlakuan pupuk pocket. Secara umum, semakin dalam lapisan tanah maka produksi akar semakin menurun. Hal tersebut dapat disebabkan karena kandungan unsur hara paling banyak berada pada lapisan atas, dan kandungan tersebut semakin berkurang dengan semakin turunnya lapisan tanah. Dari hasil penelitian dapat dilihat secara umum akar tanaman kelapa sawit pada perlakuan dengan metode sebar, memiliki produksi akar yang relatif lebih tinggi jika dibandingkan dengan metode pocket. Produksi akar primer pada perlakuan pupuk sebar di kedalaman 0 $20 \mathrm{~cm}, 20-40 \mathrm{~cm}, 40-60 \mathrm{~cm}$, dan $80-$ $100 \mathrm{~cm}$ lebih tinggi jika dibandingkan dengan perlakuan pocket. 
Produksi akar primer antara perlakuan pemupukan menggunakan metode pocket dengan metode sebar pada kedalaman $20 \mathrm{~cm}-40 \mathrm{~cm}$ mempunyai perbedaan nilai yang cukup mencolok. Dari Gambar 4 dapat dilihat bahwa produksi akar yang dihasilkan pada metode sebar $(23,06 \mathrm{~kg})$ jauh lebih tinggi dibandingkan dengan produksi akar pada perlakuan pemupukan metode pocket $(4,91$ kg). Pada kedalaman $40-60 \mathrm{~cm}$ produksi akar kedua perlakuan menunjukkan hasil yang relatif sama antara perlakuan pupuk sebar dengan pupuk pocket dengan nilai berturut - turut sebesar 3,17 kg dan 3,16 kg. Namun pada kedalaman $60 \mathrm{~cm}-80$ $\mathrm{cm}$, produksi akar perlakuan pemupukan metode pocket memiliki nilai yang lebih tinggi jika dibandingkan dengan metode sebar.

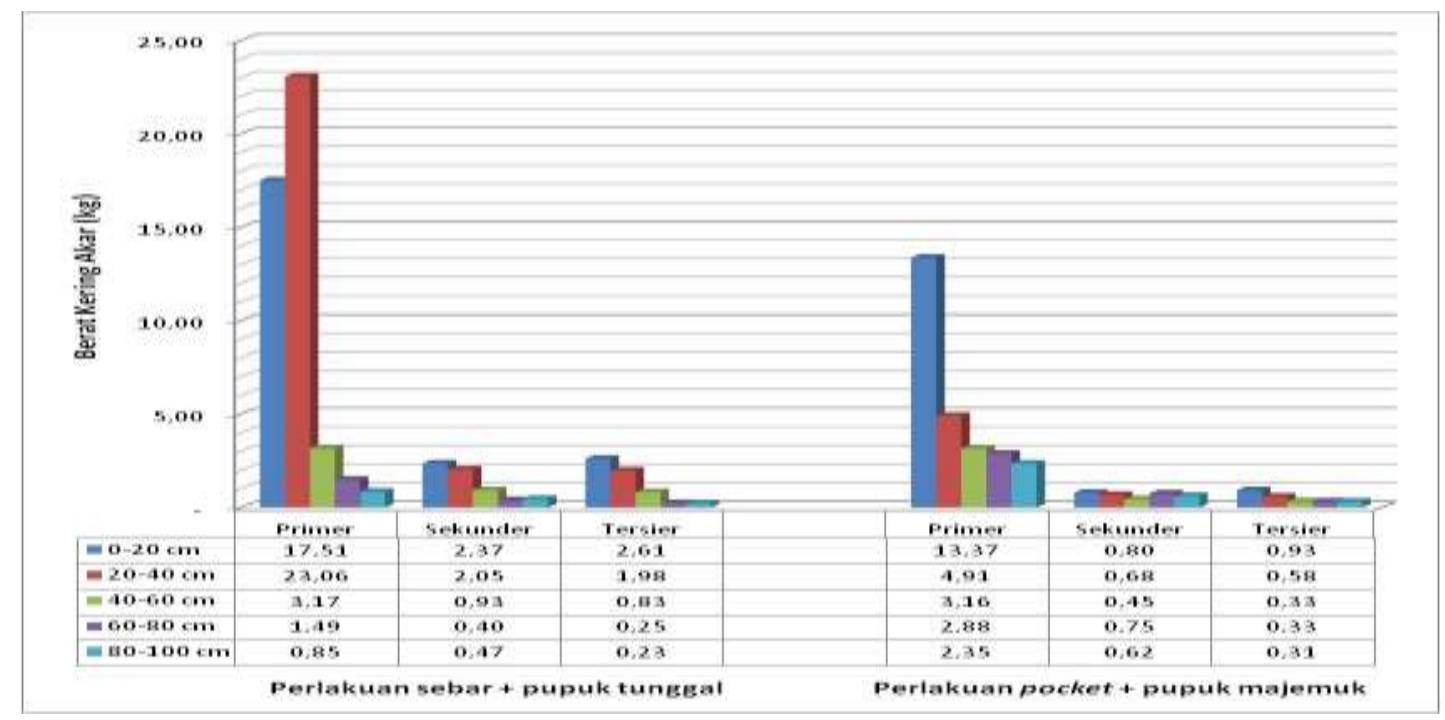

Gambar 4. Rerata produksi akar pada tanaman kelapa sawit yang diberi pupuk dengan cara pocket dan cara standar pada kedalaman $0-100 \mathrm{~cm}$.

Pada metode aplikasi pemupukan dengan cara pocket, produksi akar di kedalaman $40-100$ $\mathrm{cm}$ lebih tinggi jika dibandingkan dengan metode sebar. Hal ini disebabkan karena perkembangan akar sangat dipengaruhi oleh ketersediaan unsur hara (Machado et al., 2003). Pada metode pocket, unsur hara di tempatkan pada lubang pocket, sehingga ketersediaan hara hanya terkonsentrasi disekitar lubang pocket. Sedangkan aplikasi pupuk dengan metode sebar, pemupukan dilakukan dengan cara menebar pupuk pada piringan. Hal tersebut mengakibatkan konsentrasi tersebar merata di seluruh piringan, sehingga ketersediaaan hara bagi akar dapat terpenuhi secara merata. Hal ini mengakibatkan pertumbuhan akar pada aplikasi pupuk dengan cara sebar rata - rata lebih tinggi produksi akarnya nya dibandingkan dengan perlakuan pocket pada kedalaman 0 - $40 \mathrm{~cm}$. Pada metode pocket penyebaran pupuk tidak merata, hanya pada bagian tertentu saja yang terdapat konsentrasi pupuk tinggi. Sehingga hanya pada bagian tersebut produktifitas akar tinggi.

Pada perlakuan sebar dan perlakuan pocket memiliki pola distribusi akar primer yang sama. Produksi akar primer pada jarak 0 $50 \mathrm{~cm}$ dari tanaman memiliki nilai produksi akar yang paling tinggi 
dibandingkan dengan jarak $50-400$ $\mathrm{cm}$ dan semakin menurun sampai dengan kedalaman $100-150 \mathrm{~cm}$. Pola distribusi akar pada perlakuan sebar dan pocket di kedalaman 150 $400 \mathrm{~cm}$ memiliki pola yang sangat berbeda. Produksi akar primer pada perlakuan sebar menurun seiring dengan menurunnya kedalaman lapisan. Pola tersebut berbeda dengan pola distribusi akar pada perlakuan pocket. Perlakuan pocket di kedalaman 150 - $400 \mathrm{~cm}$ memiliki produksi akar yang cenderung semakin naik seiring dengan bertambahnya kedalaman tanah.

Produksi akar primer, sekunder, dan tersier pada perlakuan sebar pada seluruh jarak dari pangkal tanaman memiliki nilai yang lebih tinggi dibandingkan dengan perlakuan pocket. Perbedaan produktifitas akar ini dapat di sebabkan karena perbedaan sebaran hara. Aplikasi pupuk sebar dilakukan dengan menebar pupuk secara merata pada piringan, sedangkan aplikasi pupuk dengan metode pocket dilakukan dengan membuat lubang pada jarak $\pm 100 \mathrm{~cm}$ sebagai tempat meletakkan pupuk. Sehingga pada perlakuan pocket, unsur hara cenderung hanya konsentrasi sebatas jarak $\pm 100 \mathrm{~cm}$ (Gambar 5).

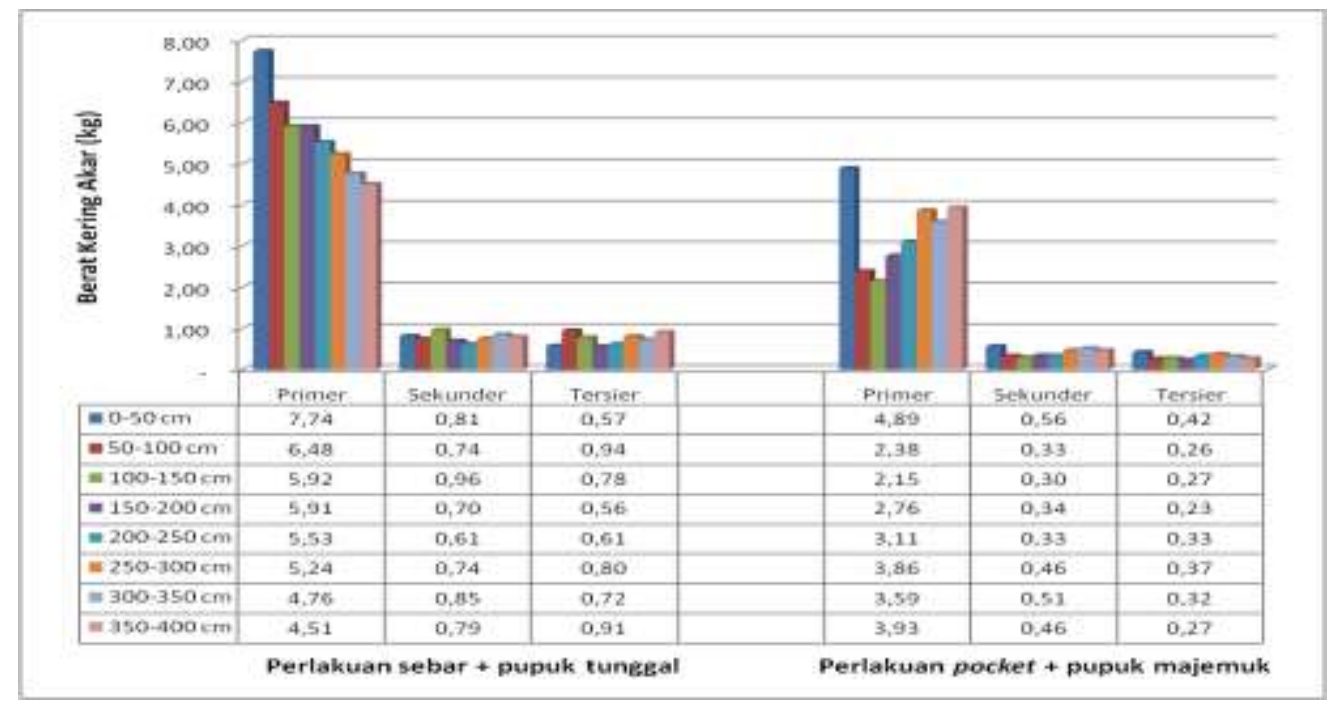

Gambar 5. Produksi akar pada tanaman kelapa sawit yang diberi pupuk dengan cara pocket dan cara standar pada jarak $0-400 \mathrm{~cm}$ dari pangkal batang.

\section{SIMPULAN}

Distribusi hara pada penelitian ini memiliki pola yang hampir sama antara perlakuan pemupukan dengan metode sebar dan perlakuan dengan metode pocket. Sebaran hara pada lapisan $0-20$ $\mathrm{cm}$ memiliki nilai yang lebih tinggi di bandingkan dengan sebaran hara yang ada di lapisan bawahnya.
Lokasi penelitian memiliki topografi bergelombang. Erosi yang terjadi sangat intensif. Dari penelitian diperoleh hasil bahwa pemupukan dengan metode pocket mampu menahan unsur hara dalam tanah lebih banyak dibandingkan dengan perlakuan sebar. Pupuk sebar pada waktu hujan lebih mudah tererosi sehingga kandungan haranya cepat hilang. Sedangkan pada perlakuan pocket unsur hara relatif lebih tertahan. 
Produksi akar semakin menurun seiring dengan penurunan lapisan tanah. Perlakuan pupuk sebar memiliki produksi akar yang lebih tinggi dibandingkan dengan dengan perlakuan pocket.

\section{DAFTAR PUSTAKA}

Adiputra, R. 2009. Hubungan antara serapan hara dan kerapatan akar. http://one.indoskripsi.com/judulskripsi-makalah-tentang/hubunganantara-serapan-hara-dan-kerapatanakar.

Kheong, L. V., Z. A. Rahman, M. H. Musa, and A. Hussein. 2010. Nutrient absorbtion by oil palm primary roots as affected by empty fruit bunch aplication. Journal of Oil Palm Research, Vol. 22 April 2010 p. 711-720.

Lubis, A. U. 2008. Kelapa sawit (Elaeis guineensis jacq.) di Indonesia. Pusat Penelitian Kelapa Sawit.

Widyastuti H., E. Guharja,N. Sukarno, L.K. Darusman, D.H.Goenadi, dan S. Smith. 2003. Arsitektur akar bibit kelapa sawit yang diinokulasi beberapa cendawan mikoriza arbuskula. Menara Perkebunan, 71(1): $28-43$.
Machado, R. M. A., Maria do Rosario, G. Oliveira, dan C. A. M. Portas. 2002. Plant and Soil 2003, 255: 333-341.

Martoyo, K. 1992. Kajian sifat fisik tanah podsolik untuk tanaman kelapa sawit (Elaeis guineensis Jacq) di Sumatera Utara. Tesis. Program Studi Ilmu Tanah. Jurusan Ilmu Ilmu Pertanian UGM.

Riata, R. 2010. Unsur hara dan dinamikanya bagi tanaman. http://ritariata.blogspot.com/ 2010/03/unsur-hara-dandinamikanya-bagi_02.html. Diakses pada tanggal 25 Juni 2010.

Soil Survey Staf USDA. 2003.Keys to soil taksonomy.

Tinker, P. B. 1976. Soil requirements of the oil palm. In R. H. V. Corley, J. J. Hardon, B. J. Wood (Ed.). Oil palm Research. Elsevier Scientific Publishing Company, p. 165 - 181.

Yahya, Z., A. Husin, J. Talib, J. Othman, O. H. Ahmed, and M. B. Jalloh. 2010. Oil Palm (Elaeis guineensis) roots response to mechanization in bernam series soil. American Journal of Applied Sciences, 7 (3): 343-348. 
Lampiran 1

Sebaran unsur hara pada perlakuan sebar dengan menggunakan pupuk tunggal

Unsur N

\begin{tabular}{|c|c|c|c|c|c|c|c|c|c|}
\hline \multirow{2}{*}{ Kedalaman } & \multicolumn{8}{|c|}{ Jarak dari pohon } & \multirow{2}{*}{ Rerata } \\
\hline & 50 & 100 & 150 & 200 & 250 & 300 & 350 & 400 & \\
\hline $0-20$ & 0,10 & 0,12 & 0,15 & 0,13 & 0,11 & 0,11 & 0,11 & 0,09 & 0,12 \\
\hline $20-40$ & 0,06 & 0,05 & 0,07 & 0,07 & 0,11 & 0,11 & 0,08 & 0,09 & 0,08 \\
\hline $40-60$ & 0,08 & 0,08 & 0,07 & 0,07 & 0,07 & 0,07 & 0,08 & 0,07 & 0,07 \\
\hline $60-80$ & 0,06 & 0,06 & 0,06 & 0,06 & 0,07 & 0,06 & 0,06 & 0,06 & 0,06 \\
\hline $80-100$ & 0,06 & 0,06 & 0,06 & 0,06 & 0,05 & 0,05 & 0,05 & 0,05 & 0,06 \\
\hline rerata & 0,07 & 0,07 & 0,08 & 0,08 & 0,08 & 0,08 & 0,08 & 0,07 & \\
\hline
\end{tabular}

\section{Unsur P}

\begin{tabular}{|c|c|c|c|c|c|c|c|c|c|}
\hline \multirow{2}{*}{ Kedalaman } & \multicolumn{8}{|c|}{ Jarak dari pohon } & \multirow{2}{*}{ Rerata } \\
\hline & 50 & 100 & 150 & 200 & 250 & 300 & 350 & 400 & \\
\hline $0-20$ & 74 & 54 & 43 & 15 & 3 & 3 & 11 & 13 & 27,00 \\
\hline $20-40$ & 5 & 2 & 7 & 4 & 2 & 1 & 2 & 3 & 3,25 \\
\hline $40-60$ & 2 & 2 & 1 & 1 & 2 & 1 & 2 & 2 & 1,63 \\
\hline $60-80$ & 5 & 1 & 4 & 39 & 1 & 1 & 1 & 1 & 6,63 \\
\hline $80-100$ & 1 & trace & 1 & 1 & 1 & 1 & 1 & 1 & 1,00 \\
\hline rerata & 17,40 & 14,75 & 11,20 & 12,00 & 1,80 & 1,40 & 3,40 & 4,00 & \\
\hline
\end{tabular}

\section{Unsur K}

\begin{tabular}{|c|c|c|c|c|c|c|c|c|c|}
\hline \multirow{2}{*}{ Kedalaman } & \multicolumn{8}{|c|}{ Jarak dari pohon } & \multirow{2}{*}{ Rerata } \\
\hline & 50 & 100 & 150 & 200 & 250 & 300 & 350 & 400 & \\
\hline $0-20$ & 0,33 & 0,81 & 1,57 & 1,52 & 0,13 & 0,11 & 0,17 & 0,10 & 0,59 \\
\hline $20-40$ & 0,32 & 0,62 & 0,45 & 0,23 & 0,14 & 0,14 & 0,10 & 0,16 & 0,27 \\
\hline $40-60$ & 0,18 & 0,18 & 0,10 & 0,08 & 0,06 & 0,08 & 0,11 & 0,13 & 0,12 \\
\hline $60-80$ & 0,06 & 0,04 & 0,05 & 0,05 & 0,05 & 0,05 & 0,08 & 0,10 & 0,06 \\
\hline $80-100$ & 0,04 & 0,04 & 0,06 & 0,05 & 0,05 & 0,06 & 0,07 & 0,13 & 0,06 \\
\hline rerata & 0,19 & 0,34 & 0,45 & 0,39 & 0,09 & 0,09 & 0,11 & 0,12 & \\
\hline
\end{tabular}

Unsur Mg

\begin{tabular}{|c|c|c|c|c|c|c|c|c|c|}
\hline \multirow{2}{*}{ Kedalaman } & \multicolumn{8}{|c|}{ Jarak dari pohon } & \multirow{2}{*}{ Rerata } \\
\hline & 50 & 100 & 150 & 200 & 250 & 300 & 350 & 400 & \\
\hline $0-20$ & 1,83 & 3,38 & 3,38 & 2,45 & 1,10 & 0,99 & 1,14 & 1,07 & 1,92 \\
\hline $20-40$ & 0,87 & 1,90 & 2,06 & 1,69 & 0,92 & 1,07 & 0,78 & 1,08 & 1,30 \\
\hline $40-60$ & 1,03 & 0,95 & 0,65 & 0,80 & 0,89 & 0,98 & 1,48 & 1,28 & 1,01 \\
\hline $60-80$ & 0,79 & 0,90 & 0,75 & 1,02 & 1,37 & 1,29 & 1,63 & 1,44 & 1,15 \\
\hline $80-100$ & 1,02 & 1,17 & 0,98 & 1,16 & 1,11 & 1,44 & 1,48 & 1,53 & 1,24 \\
\hline rerata & 1,11 & 1,66 & 1,56 & 1,42 & 1,08 & 1,15 & 1,30 & 1,28 & \\
\hline
\end{tabular}

\section{Unsur Ca}

\begin{tabular}{|c|c|c|c|c|c|c|c|c|c|}
\hline \multirow{2}{*}{ Kedalaman } & \multicolumn{8}{|c|}{ Jarak dari pohon } & \multirow{2}{*}{ Rerata } \\
\hline & 50 & 100 & 150 & 200 & 250 & 300 & 350 & 400 & \\
\hline $0-20$ & 3,71 & 4,76 & 6,95 & 5,94 & 3,57 & 4,61 & 4,15 & 3,68 & 4,67 \\
\hline $20-40$ & 2,35 & 8,40 & 8,61 & 6,42 & 3,76 & 5,09 & 2,46 & 3,28 & 5,05 \\
\hline $40-60$ & 4,84 & 8,13 & 5,63 & 4,82 & 4,40 & 3,89 & 3,36 & 3,31 & 4,80 \\
\hline $60-80$ & 2,64 & 5,99 & 7,19 & 6,43 & 4,43 & 3,97 & 2,80 & 3,49 & 4,62 \\
\hline $80-100$ & 1,83 & 4,83 & 5,92 & 5,02 & 3,19 & 3,78 & 2,85 & 4,42 & 3,98 \\
\hline rerata & 3,07 & 6,42 & 6,86 & 5,73 & 3,87 & 4,27 & 3,12 & 3,64 & \\
\hline
\end{tabular}


Lampiran 2

Sebaran unsur hara pada perlakuan pocket dengan menggunakan pupuk majemuk

Unsur N

\begin{tabular}{|c|c|c|c|c|c|c|c|c|c|}
\hline \multirow{2}{*}{ Kedalaman } & \multicolumn{8}{|c|}{ Jarak dari pohon } & \multirow{2}{*}{ Rerata } \\
\hline & 50 & 100 & 150 & 200 & 250 & 300 & 350 & 400 & \\
\hline $0-20$ & 0,21 & 0,12 & 0,12 & 0,13 & 0,15 & 0,15 & 0,14 & 0,14 & 0,15 \\
\hline $20-40$ & 0,11 & 0,10 & 0,10 & 0,09 & 0,11 & 0,10 & 0,08 & 0,09 & 0,10 \\
\hline $40-60$ & 0,08 & 0,07 & 0,08 & 0,09 & 0,09 & 0,09 & 0,07 & 0,09 & 0,08 \\
\hline $60-80$ & 0,07 & 0,07 & 0,07 & 0,07 & 0,07 & 0,07 & 0,06 & 0,07 & 0,07 \\
\hline $80-100$ & 0,05 & 0,05 & 0,06 & 0,07 & 0,07 & 0,07 & 0,06 & 0,06 & 0,06 \\
\hline rerata & 0,10 & 0,08 & 0,09 & 0,09 & 0,10 & 0,10 & 0,08 & 0,09 & \\
\hline
\end{tabular}

Unsur P

\begin{tabular}{|c|c|c|c|c|c|c|c|c|c|}
\hline \multirow{2}{*}{ Kedalaman } & \multicolumn{8}{|c|}{ Jarak dari pohon } & \multirow{2}{*}{ Rerata } \\
\hline & 50 & 100 & 150 & 200 & 250 & 300 & 350 & 400 & \\
\hline $0-20$ & 150 & 174 & 5 & 2 & 2 & 2 & 3 & 2 & 42,50 \\
\hline $20-40$ & 27 & 3 & 2 & 1 & 4 & 1 & 1 & 1 & 5,00 \\
\hline $40-60$ & 1 & 1 & trace & trace & trace & 1 & 1 & trace & 1,00 \\
\hline $60-80$ & 1 & 1 & 1 & trace & trace & 1 & 1 & 1 & 1,00 \\
\hline $80-100$ & 1 & 1 & 1 & 1 & 1 & 1 & 1 & 1 & 1,00 \\
\hline rerata & 36,00 & 36,00 & 2,25 & 1,33 & 2,33 & 1,20 & 1,40 & 1,25 & \\
\hline
\end{tabular}

\section{Unsur K}

\begin{tabular}{|c|c|c|c|c|c|c|c|c|c|}
\hline \multirow{2}{*}{ Kedalaman } & \multicolumn{8}{|c|}{ Jarak dari pohon } & \multirow{2}{*}{ Rerata } \\
\hline & 50 & 100 & 150 & 200 & 250 & 300 & 350 & 400 & \\
\hline $0-20$ & 1,24 & 0,30 & 0,19 & 0,21 & 0,19 & 0,21 & 0,20 & 0,21 & 0,34 \\
\hline $20-40$ & 0,57 & 0,34 & 0,21 & 0,16 & 0,17 & 0,22 & 0,21 & 0,22 & 0,26 \\
\hline $40-60$ & 0,30 & 0,30 & 0,34 & 0,29 & 0,21 & 0,32 & 0,32 & 0,32 & 0,30 \\
\hline $60-80$ & 0,33 & 0,28 & 0,38 & 0,29 & 0,30 & 0,27 & 0,29 & 0,32 & 0,31 \\
\hline $80-100$ & 0,29 & 0,34 & 0,26 & 0,36 & 0,31 & 0,31 & 0,32 & 0,34 & 0,32 \\
\hline rerata & 0,55 & 0,31 & 0,28 & 0,26 & 0,24 & 0,27 & 0,27 & 0,28 & \\
\hline
\end{tabular}

\section{Unsur Mg}

\begin{tabular}{|c|c|c|c|c|c|c|c|r|r|}
\hline \multirow{2}{*}{ Kedalaman Jarak dari pohon } & \multirow{2}{*}{ Rerata } \\
\cline { 2 - 11 } & 50 & 100 & 150 & 200 & 250 & 300 & 350 & 400 & \\
\hline $0-20$ & 7,59 & 3,75 & 3,42 & 4,07 & 3,48 & 3,64 & 4,18 & 4,81 & $\mathbf{4 , 3 7}$ \\
\hline $20-40$ & 4,91 & 4,21 & 3,34 & 2,87 & 3,51 & 5,76 & 5,69 & 5,22 & $\mathbf{4 , 4 4}$ \\
\hline $40-60$ & 6,00 & 5,70 & 5,93 & 5,34 & 4,69 & 8,32 & 11,35 & 6,82 & $\mathbf{6 , 7 7}$ \\
\hline $60-80$ & 8,43 & 4,77 & 7,30 & 5,77 & 6,81 & 7,92 & 9,80 & 7,41 & $\mathbf{7 , 2 8}$ \\
\hline $80-100$ & 9,96 & 12,28 & 5,79 & 8,12 & 7,42 & 8,85 & 11,39 & 9,43 & $\mathbf{9 , 1 6}$ \\
\hline rerata & $\mathbf{7 , 3 8}$ & $\mathbf{6 , 1 4}$ & $\mathbf{5 , 1 6}$ & $\mathbf{5 , 2 3}$ & $\mathbf{5 , 1 8}$ & $\mathbf{6 , 9 0}$ & $\mathbf{8 , 4 8}$ & $\mathbf{6 , 7 4}$ & \\
\end{tabular}

\section{Unsur Ca}

\begin{tabular}{|c|c|c|c|c|c|c|c|c|c|}
\hline \multirow{2}{*}{ Kedalaman } & \multicolumn{8}{|c|}{ Jarak dari pohon } & \multirow{2}{*}{ Rerata } \\
\hline & 50 & 100 & 150 & 200 & 250 & 300 & 350 & 400 & \\
\hline $0-20$ & 8,41 & 3,84 & 2,31 & 3,25 & 4,12 & 3,53 & 3,68 & 3,73 & 4,11 \\
\hline $20-40$ & 1,88 & 0,52 & 0,69 & 0,59 & 1,12 & 2,49 & 2,77 & 2,45 & 1,56 \\
\hline $40-60$ & 0,96 & 0,50 & 0,90 & 1,21 & 1,89 & 5,46 & 6,37 & 3,64 & 2,62 \\
\hline $60-80$ & 3,56 & 0,61 & 2,98 & 2,31 & 3,83 & 6,37 & 7,23 & 5,65 & 4,07 \\
\hline $80-100$ & 6,87 & 7,14 & 4,46 & 5,89 & 6,54 & 8,32 & 9,48 & 8,36 & 7,13 \\
\hline rerata & 4,34 & 2,52 & 2,27 & 2,65 & 3,50 & 5,23 & 5,91 & 4,77 & \\
\hline
\end{tabular}

